\title{
Efectos de la magnesia sobre la combinación de la cal en el clínker
}

Niels hesselluerg Christenssen. F. L. Smidith \& Co. Copenhagen World Cement Technology. Octubre 1978

El autor se propone, en este muy apreciable artículo, poner de manifiesto que la magnesia en el clínker de portland no es un constituyente "traza" sino que tiene efectos pequeños pero distintos en la calcinación del clínker, diferentes del efecto perjudicial que ejercería en la estabilidad del hormigón, motivo de su limitación al $6 \%$ en la mayoría de las normas que condicionan al cemento portland.

\section{El contenido máximo de cal}

El factor de saturación utilizado hoy día se debe a Lea y Parker, que lo formularon en $1935(1-2)$.

$$
F=\frac{C}{2,85+1,18 a+0,65 f}
$$

El denominador, considerado como el máximo contenido de cal, expresa el máximo contenido de cal que puede estar presente sin que aparezca cal libre a la temperatura de clinkerización en equilibrio con la porción líquida presente.

Con los datos que en la literatura aparecen (2, págs. 344, 363, 411) se exponen los cálculos para obtener la expresión del contenido máximo de cal en los siguientes sistemas:

\section{Sistema I:}

$$
\begin{array}{lll}
C+A+S & C_{\mathrm{m}}=2,85+1,18 a & F=\frac{C}{2,85+1,18 a} \\
C+A-S+F & C_{\mathrm{m}}=2,85+1,18 a+0,66 f & F=\frac{C}{2,85+1,18 a+0,66 \mathrm{f}} \\
C+A+S+M & C_{\mathrm{m}}=2,85+1,18 a-0,93 m & F=\frac{C}{2,85+1,18 a-0,93 m} \\
C+A+S+F+M & C_{\mathrm{m}}=2,85+1,18 a+0,66 f & F=\frac{C+0,77 m}{2,85}+1,18 a+0,66 \mathrm{f}
\end{array}
$$




\section{Sistema II:}

$$
\begin{array}{ll}
C-A-S & C_{\mathrm{m}}=2,85+1,18 a \\
C-A-S-F & C_{\mathrm{m}}=2,85+1,18 a+0,66 f \\
C-A-S-M & C_{\mathrm{m}}=2,85+1,18 a+0,93 \mathrm{~m} \\
C-A-S-F-M & C_{\mathrm{m}}=2,85+1,18 a+0,66 f
\end{array}
$$

pero el factor de saturación toma la forma:

$$
F=\frac{C+0,77 m}{2,85+1,18 a+0,66 f}
$$

\section{Primeras evidencias experimentales}

La posibilidad de que sea necesario incluir en la fórmula de saturación de cal un término para la magnesia, fue discutida ya en 1938 por Lea (3). El derivó la fórmula $C_{\mathrm{m}}=2,85+$ $+1,18 a \longrightarrow 0,93 m$ y anticipó que se debía añadir un término de corrección debido a la influencia combinada del hierro y la magnesia. Presentó datos en apoyo de su tesis, pero llegó a la conclusión que el efecto sería pequeño.

Un análisis actual de estos datos conduce a una fórmula con un significativo valor estadístico para la magnesia.

En 1969 Spohn y colaboradores (4) publicaron extensos datos sobre clínker, en equilibrio saturado de cal, y sugirieron la fórmula:

$$
F=\frac{C+0,75 m}{2,85+1,18 a+0,66 f}
$$

Estos autores han demostrado que una parte sustancial de magnesia entra en la red del silicato tricálcico reemplazando a la cal.

\section{Efecto sobre la clinkerización}

Considerando las mezclas usuales no saturadas se puede llegar a concluir que la adición de $\mathrm{MgO}$ a tales mezclas sería un impedimento para la combinación de la cal. La experiencia demuestra que el efecto contrario es más probablemente observado.

Especialmente con los áridos blancos calcinados a temperaturas relativamente bajas, la adición de magnesia puede acrecentar la combinación de la cal.

Como ejemplo, menciona una experiencia de laboratorio sobre un crudo industrial para cemento blanco cuya composición fue: $14,9 \% \mathrm{SiO}_{2} ; 3,79 \% \mathrm{Al}_{2} \mathrm{O}_{3} ; 0,07 \% \mathrm{Fe}_{2} \mathrm{O}_{3} ; 43,9 \%$ $\mathrm{CaO}$ y $0,6 \% \mathrm{MgO}$.

Después de 30 minutos a $1.400^{\circ} \mathrm{C}$, el clínker contenía $5,3 \%$ de cal libre. Se añadió magnesia hasta hacer un total de $1,1 \%$ de $\mathrm{MgO}$, cuidando no causar molturación adicional. El 
clínker calcinado de este material, bajo idénticas condiciones, sólo contenía $2,1 \%$ de cal libre.

Esto se explica teniendo en cuenta que el factor $F$ era $95 \%$, debido entonces a incompleta reacción por falta de equilibrio; la clinkerización se mejora al aumentar la formación de líquido (fundido) y, en cierto límite, el incremento de magnesia causa aumento de fase líquida. Particularmente cierto en el clínker blanco entre $1.380-1.450^{\circ} \mathrm{C}$.

\section{Conclusiones}

La magnesia, en contraste con el óxido férrico y la alúmina, reduce el contenido de cal combinable de un crudo y debe añadirse un término correctivo a la fórmula de Lea y Parker. Con los moderados valores de $F$ usados en los cementos tradicionales, puede ser difícil comprobar ese efecto a causa de que la velocidad de combinación de la cal se puede incrementar por el contenido de magnesia adicional.

\section{R E F E R E N C I A S}

(1) Lea, F. M. y Parker, T. W.: Building Research Technical. Paper n.* 16.1935.

(2) Bogue, R. H.: The Chemistry of Portland Cement Reinhol. Pb. Cop. N. York. 1935.

(3) LEA, F. M.: Symposium on Chemistry of Cements. Stockholm. 1938. Proceedings, p. 125.

(4) Spor, N.: Proceedings of the Fifth International, Simposium on Chemistry of Cement. Part. 1. Vol. 1. 1969. Tokyo, pp. 172-179. 